\title{
Kontrolle von Mehrheitsbeteiligungen in börsennotierten Management-Holdings
}

\author{
Markus Eckey • Utz Schäffer
}

Published online: 12 January 2007

(C) Springer-Verlag 2007

\section{Erratum to: Zeitschrift für Planung \& Unternehmenssteuerung DOI 10.1007/s00187-006-0003-y}

In der Abb. 1 auf S. 273 ist der rechte Rand abgeschnitten worden, so dass die im Strukturmodell zugelassene Korrelation der Fehlervariablen der beiden Erfolgsvariablen Effektivität und Effizienz der Kontrolle nicht ersichtlich ist. Es fehlen in Abb. 1 mithin die Verbindung zwischen Effektivität und Effizienz der Kontrolle sowie der zugehörige standardisierte Koeffizient von 0,19, der ein Signifikanzniveau von 5\% aufweist.

The online version of the original article can be found at http://dx.doi.org/10.1007/s00187-006-0003-y

Dr. M. Eckey $(\varpi) \cdot$ Prof. Dr. U. Schäffer $(\varpi)$

European Business School, International University Schloss Reichartshausen, Lehrstuhl für Controlling, 65375 Oestrich-Winkel, Deutschland

e-mail: markus.eckey@db.com

e-mail: utz.schaeffer@gmx.de 


\section{Hier die richtige Darstellung:}

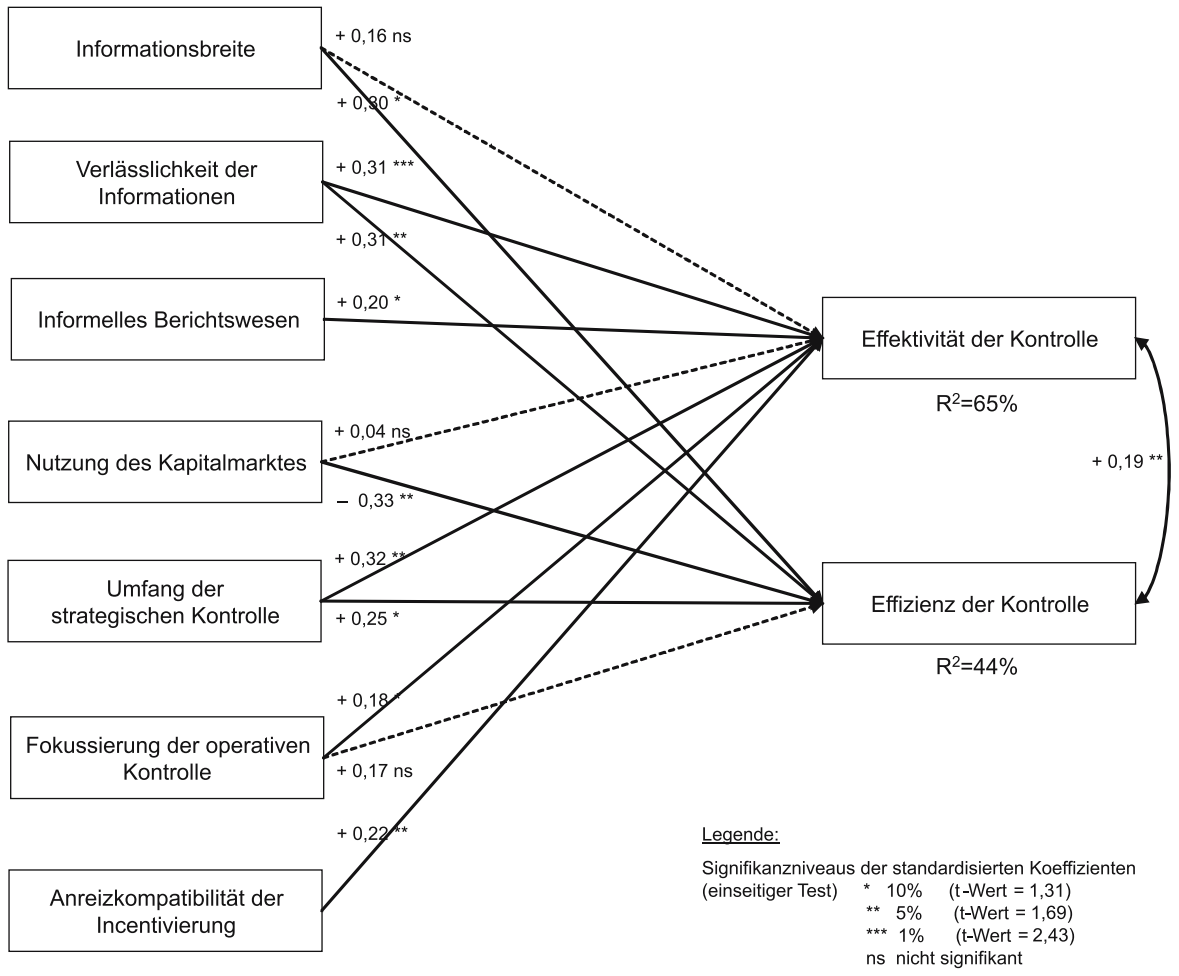

Abb. 1 Modell zur Überprüfung der Zusammenhänge zwischen Gestaltung und Erfolg der Kontrolle (standardisierte Lösung) 